\title{
Bestatin, an Aminopeptidase Inhibitor, Promotes Follicular Growth and Ovulation Suppressed by Stress in Mice
}

\author{
KimiHIKo NAKAMURA, Hiroshi FUJIWARA, ToshIHIRo HIGUCHI, Tetsuro HONDA, \\ SHIGETOSHI YAMADA, TAKAHIRO NAKAYAMA, JUn FUJITA*, MichIYUKI MAEDA**, \\ TOSHIYUKI TACHIBANA***, HIROSHI SUGINAMI" AND TAKAHIDE MORI \\ Department of Gynecology and Obstetrics, Faculty of Medicine, *Clinical Molecular Biology, \\ **Chest Disease Research Institute, Kyoto University, Kyoto 606-01, \\ ***Department of Obstetrics and Gynecology, Fukui Red Cross Hospital, Fukui 910 , \\ \#Department of Obstetrics and Gynecology, Kyoto National Hospital, Kyoto 612, Japan
}

\begin{abstract}
We previously reported that the intraperitoneal and intrabursal administration of bestatin, an aminopeptidase inhibitor, enhanced follicular growth and ovulation in immature mice. In this study, we examined the effect of bestatin on follicular growth and ovulation under the conditions in which the ovarian response to gonadotropins was suppressed. Immature female mice were exposed to 72-h continuous lighting (on days 20-22 of life), or to 24-h starvation (on day 20). On days 20-22, bestatin (4 $\mathrm{mg} / \mathrm{ml}, 100 \mu l)$ or PBS $(100 \mu l)$ was administered ip. 4 times and pregnant mare serum gonadotropin (PMSG, $5 \mathrm{IU}$ ) and hCG (5 IU) were given on days 21 and 23, respectively. The numbers of ovulated oocytes per mice were significantly attenuated by both stresses. Bestatin significantly enhanced the numbers of ovulated oocytes under both lighting (49.5 $\pm 7.0 \mathrm{vs} .28 .0 \pm 5.5)$ and starvation (28.6 $\pm 2.6 \mathrm{vs}$. $20.2 \pm 2.0$ ) stresses (with $v s$. without bestatin, $P<0.05$ ). When follicular development was stimulated by PMSG (20 IU) on day 21, the serum estradiol concentration on day 23 was also suppressed by both stresses, but enhanced by bestatin under lighting $(231.3 \pm 36.0 \mathrm{vs} .111 .0 \pm 23.0 \mathrm{pg} / \mathrm{ml})$ and starvation $(151.9 \pm 8.8$ vs. $90.7 \pm 15.4 \mathrm{pg} / \mathrm{ml}$ ) stresses (with $v s$. without bestatin, $P<0.01)$. Northern blot analysis revealed that the expression of P450arom-mRNA in the ovaries induced by PMSG (20 IU) was increased on day 23 by treatment with bestatin under starvation stress. These results indicated that stress inhibited the ovarian response to gonadotropins and that bestatin restored the response suppressed by stress.
\end{abstract}

Key words: Bestatin, Stress, Follicular growth, Ovulation

(Endocrine Journal 45: 547-553, 1998)

WE REPORTED that human theca interna cells express aminopeptidase-N (AP-N) during folliculogenesis and proposed that AP-N is a differentiation-related molecule of human theca interna cells $[1,2]$. AP-N is a membrane-bound aminopeptidase and has an extracellular catalytic

Received: June 16, 1997

Accepted: May 12, 1998

Correspondence to: Dr. Hiroshi FUJIWARA, Department of Gynecology and Obstetrics, Faculty of Medicine, Kyoto University, Sakyo-ku, Kyoto 606-01, Japan site. AP-N is reported to degrade small molecular peptides such as enkephalin, somatostatin, angiotensins I and II, and met-lys-bradykinin [3, 4]. The removal of one or two amino acids from the N-terminal of polypeptides destabilizes the substrate molecule by a conformational change or by permitting access of the substrate to further degradation by other enzymes [5]. We therefore proposed that membrane-bound peptidases are involved in cellular growth and differentiation of ovarian cells [6], and speculated the presence of an intrafollicular peptidase regulatory system in which 
membrane-bound peptidases extracellularly modify the interaction between peptides and their specific receptors in the follicles [1].

To elucidate the physiological significance of AP$\mathrm{N}$, the effect of bestatin, a potent inhibitor, on follicular growth and ovulation was examined in pregnant mare serum gonadotropin (PMSG)primed and hCG-induced immature mice, since AP-N was immunohistochemically identified in the theca-interstitial cells and AP-N-like activity was also detected in both theca-interstitial and granulosa cells in the murine ovaries. The intraperitoneal and intrabursal administration of bestatin significantly enhanced mouse follicular growth and ovulation [7]. Bestatin is a low molecular weight dipeptide isolated from the culture filtrate of Streptomycine olivoreticuli by Umezawa et al. [8], and binds to cell surfaces and inhibits cell-surface aminopeptidases including AP-N [9]. It also inhibits aminopeptidase- $B$ and leucine aminopeptidase [8]. Bestatin is reported to affect the function of macrophages, $\mathrm{T}$ lymphocytes and bone marrow progenitor cells by binding to these aminopeptidases [10], and to stimulate the immune system. Bestatin may exert its biological effects via inhibition of the cell-surface aminopeptidases, but this remains to be proven [9]. Since bestatin has the biological activity of an immunomodulator as described above, and has extremely low toxicity, clinical application to drug therapy has been investigated [11]. At present, it is applied clinically as an oral immunostimulant for patients with leukemia, and few side effects have been reported in Japan. Although the precise mechanism of the effect of bestatin on murine follicular growth and ovulation remains unknown, we proposed the potential usefulness of this reagent for clinical application [7].

In this study, we used two stress conditions, i.e. lighting and starvation, under which the response of the ovaries to exogenous gonadotropins was impaired. To evaluate the clinical application of bestatin to the patients such as poor responders for exogenous gonadotropins, we examined the effect of bestatin on the number of ovulated oocytes and estradiol production in response to gonadotropin in mice under these stress conditions.

\section{Materials and Methods}

\section{Reagents}

PMSG and hCG were purchased from Teikoku Zoki Co. (Tokyo, Japan). Bestatin ([(2S, 3R)-3amino-2-hydroxy-4-phenybutanoyl]-(S)-leucine), an inhibitor of AP-N [9], was a gift from Nihon Kayaku Co., Ltd. (Tokyo, Japan).

\section{Animals}

Sixteen-day-old immature female ICR mice were purchased from Charles River Japan Inc. (Kanagawa, Japan) and housed in a temperaturecontrolled room $\left(22-24{ }^{\circ} \mathrm{C}\right)$ under controlled lighting ( $14 \mathrm{~h}$ of light, $10 \mathrm{~h}$ of darkness), and given water and food ad libitum. When the mice became 20 days old, the following experiments were performed.

\section{Stress conditions}

We used two stress conditions, which were continuous lighting stress for $72 \mathrm{~h}$ from day 20 (stress-1), and starvation stress with food deprived but water provided for $24 \mathrm{~h}$ from day 20 (stress-2).

\section{Bestatin administration and the induction of follicular growth and ovulation under stress}

Under each experimental condition (stress-1 or stress-2), the mice were divided into three groups, non-stressed mice (control), bestatin-treated stressed mice and bestatin-non-treated stressed mice. Five mice were used in each group. At 1900 $\mathrm{h}$ on day $20,0700 \mathrm{~h}$ and $1900 \mathrm{~h}$ on day 21 , and $0700 \mathrm{~h}$ on day 22 , bestatin $(4 \mathrm{mg} / \mathrm{ml}$ dissolved in PBS containing $0.1 \%$ bovine serum albumin (BSA), $100 \mu l)$ or PBS containing $0.1 \%$ BSA $(100 \mu l)$ was ip. injected. In the non-stressed group, PBS containing $0.1 \%$ BSA $(100 \mu l)$ was ip. administered on the same time schedule. At $1700 \mathrm{~h}$ on day 21, in all the mice, the development of multiple follicles was induced by an ip. injection of PMSG (5 IU), and then at $1700 \mathrm{~h}$ on day 23 , hCG (5 IU) was ip. injected to induce ovulation as described [12]. The same experiments were performed five times under each stress condition, respectively. At $1200 \mathrm{~h}$ on 
day 24, the mice were killed by cervical dislocation. The number of ovulated oocytes per animal was evaluated from the number of oocytes in the bilateral oviducts by the scratching method as described [13].

Effect of bestatin on the gain of body weight in mice under starvation stress

The effect of starvation and bestatin on the body weight was examined. In the stress-2 (starvation) experiment, the body weight of the individual mouse was measured at $1700 \mathrm{~h}$ on day 20 and at $1700 \mathrm{~h}$ on day 23.

\section{Bestatin administration and blood sampling for estradiol concentration under stress}

Mice were divided into three groups as described above. Bestatin or PBS was administered as described above. At $1700 \mathrm{~h}$ on day 21, the development of multiple follicles was induced by an ip. injection of PMSG (20 IU). At $1700 \mathrm{~h}$ on day 23 , blood for measurement of the serum estradiol concentration was drawn by retro-orbital puncture under ether anesthesia. The same experiments were performed five times under each stress condition.

\section{Radioimmunoassay (RIA) of estradiol}

The concentration of estradiol in the mouse serum was measured with RIA kits (Daiichi Radioisotope Laboratories Ltd., Tokyo, Japan) as described previously [14]. The mininum detectable concentration of estradiol was $20 \mathrm{pg} / \mathrm{ml}$.

\section{RNA extraction and Northern blotting}

Under starvation stress (stress-2), the expression of mRNA of aromatase cytochrome P450 (P450arom) in the ovary was examined by Northern blotting. Mice were divided into four groups, control mice (group 1), non-stress mice (group 2), stressed mice (group 3 ) and bestatin-treated stressed mice (group 4). Five mice were used in each group. At $1900 \mathrm{~h}$ on day $20,0700 \mathrm{~h}$ and $1900 \mathrm{~h}$ on day 21 , and $0700 \mathrm{~h}$ on day 22, bestatin (group $4: 4 \mathrm{mg} / \mathrm{ml}$ dissolved in PBS containing 0.1\% BSA, $100 \mu l$ ) or PBS containing 0.1\% BSA (group 1-3: $100 \mu l$ ) was ip. injected. At $1700 \mathrm{~h}$ on day 21, the development of multiple follicles was induced by an ip. injection of PMSG (20IU) in group 2-4. At $1700 \mathrm{~h}$ on day 23, the mice were killed by cervical dislocation and the ovaries were subjected to RNA isolation. The same experiments were performed five times.

Total RNAs from mice ovaries were isolated by the TRIzol method (Life Technologies, Gaithersburg, MD, USA). Northern blotting was done as previously described [15]. Briefly, ten micrograms of total RNA was electrophoresed on a $1.0 \%$ agarose-formaldehyde gel and then transferred to nylon membranes (Hybond-N ${ }^{+}$; Amersham Corp., Arlington Heights, IL, USA). The membranes were hybridized with [ $\left.{ }^{32} \mathrm{P}\right]$-labeled DNA probes in Rapid Hyb buffer (Amersham Corp.) following the manufacturer's instructions. The probe was labeled by random primer labeling (Megaprime, Amersham Corp.) to a specific radioactivity of $0.8-1.5 \times 10^{9} \mathrm{cpm} / \mu \mathrm{g}$ DNA. The mRNA levels was calculated on the basis of the hybridized signal measured by densitometric scanning of the autoradiograph. As a control for the amount of RNA loaded, membranes were also probed with the constitutively expressed gene for $\beta$-actin, and each P450 arom-mRNA level was corrected with the level of $\beta$-actin mRNA [16]. For statistical analyses, the mean P450 arom-mRNA level in each group (groups 2-4) was expressed relative to that in group 1 in each experiment.

\section{Preparation of murine aromatase cytochrome P450 (P450arom) cDNA clone}

The cDNA clone of murine P450arom was prepared as follows. Two micrograms of murine ovarian total RNA was reverse-transcribed with random primers, with a commercial kit (First Strand cDNA Synthesis Kit; Pharmacia, Inc., Piscataway, NJ, USA). The resulting cDNA mixture was subjected to 30 cycles of polymerase chain reaction (PCR) amplification with oligonucleotides from the murine P450arom cDNA as primers [17] (sense primer 5'-ATTCTTGTGGATGGGGATTG-3': position 238-257; antisense primer 5'-AGATGTTTG GTTTGATGAGG-3': position 727-746) or with murine $\beta$-actin primers [18] (sense primer $5^{\prime}$ TCAGAAGGACTCCTATGTGG-3': position 224-243; antisense primer 5'-TCTCTTTGATGTC ACGCACG-3': position 704-723). The PCR product was cloned into a pBluescript SK( - ) plasmid, and 
the insert was verified by sequencing [15]. The inserted clones were purified and used as the murine P450arom and murine $\beta$-actin probes in Northern blot analysis.

\section{Statistical analysis}

The increase in body weight was found by subtracting the mean body weight on day 20 from that on day 23 in each experiment. Values are expressed as the mean \pm SEM of five individual experiments. The differences among the three groups were analyzed by one-way analysis of variance, followed by the Scheffe $F$ test. The difference was considered to be significant at $P<0.05$.

\section{Results}

\section{Effect of bestatin on the number of ovulated oocytes under stress}

In both stress groups (stress- 1 and -2 ), the number of ovulated oocytes in the mice without bestatin treatment was significantly smaller than that in the non-stressed mice, and was significantly increased by bestatin treatment (Fig. 1A and 1B).

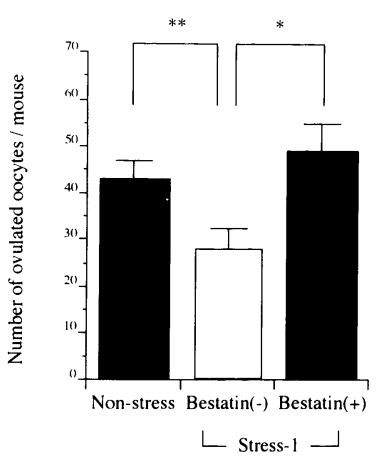

B

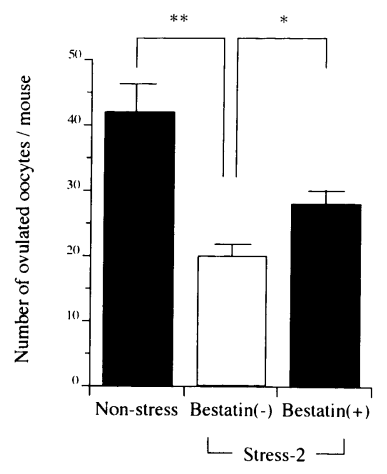

Fig. 1. The effect of bestatin administration on ovulation under continuous lighting (Stress-1, A) and starvation (Stress-2, B). The number of ovulated oocytes was reduced under each stress (non-stress $v s$. bestatin $(-))$. Bestatin enhanced stresssuppressed ovulation under each stress (bestatin $(-$ ) $v s$. bestatin $(+))$. Bars indicate the mean \pm SEM $\left({ }^{*} P<0.01,{ }^{*} P<0.05\right)$.

\section{The serum estradiol concentration}

After stimulation with a high dose of PMSG (20 IU), the estradiol concentrations of serum samples were detectable within the sensitivity range of an RIA kit. In both stress conditions (stress-1 and -2), the estradiol concentration of the mice without bestatin treatment was significantly lower than that of the non-stressed mice, and was significantly increased by bestatin treatment (Fig. 2A and 2B).

\section{Mouse body weight gain under starvation stress}

The weight gain in the starvation-stressed group either with or without bestatin treatment, was significantly lower than that in the non-stressed group. The body weight gain in the mice without bestatin treatment did not significantly differ from that in the bestatin-treated mice (Fig. 3).

\section{Expression of P450arom $m R N A$ in murine ovaries}

Administration of PMSG to immature nonstressed mice noticeably increased the ovarian P450arom mRNA levels (Fig. 4, lanes 1 and 2). The size of the detected P450arom transcripts in ovaries of nonpregnant mice was consistent with the previously reported size of $2.5 \mathrm{~kb}$ [17]. Expression
A

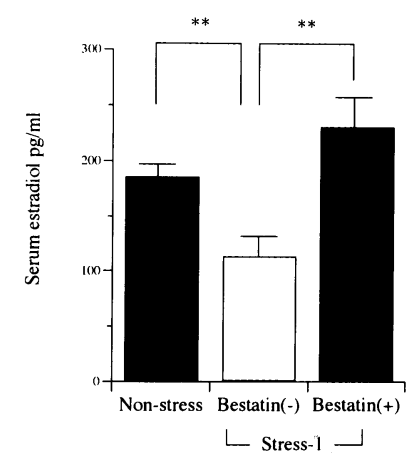

B

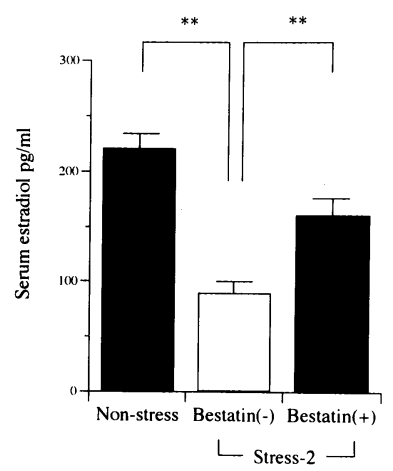

Fig. 2. The effect of bestatin administration on the serum concentration of estradiol under continuous lighting (Stress-1, A) and starvation (Stress-2, B). The serum estradiol level was decreased under each stress (non-stress $v s$. bestatin(-)). It was increased by bestatin under each stress (bestatin( -$)$ vs. bestatin( $(+))$. Bars indicate the mean \pm SEM $\left({ }^{* *} P<0.01\right)$ 


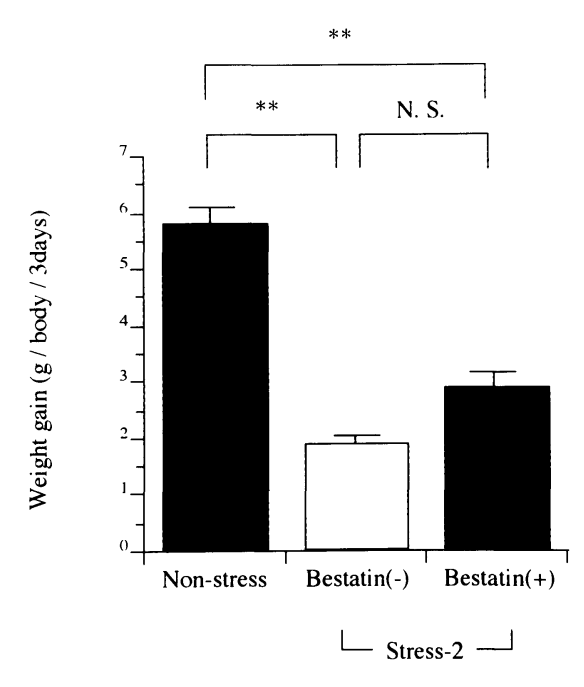

Fig. 3. The weight gain of mice under starvation stress. The body weight gains (from day 20 to day 23 of age) in the mice with or without bestatin treatment under Stress-2 (starvation) and in non-stressed mice were measured. Starvation stress reduced body weight gain $(* * P<0.01)$, whereas bestatin did not have a significant effect on body weight gain (N.S.). Bars indicate the mean \pm SEM.

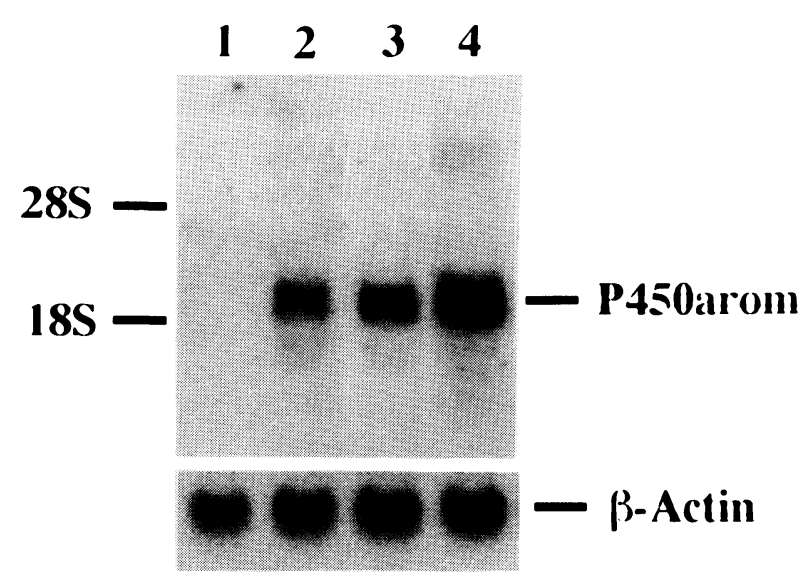

Fig. 4. The expression of P450arom-mRNA in the murine ovaries under starvation stress. The expression of P450 arom-mRNA was examined by Northern blotting. Lane 1: mouse ovaries without bestatin treatment, without PMSG stimulation, and without starvation stress. Lane 2: mouse ovaries without bestatin, with PMSG, and without starvation stress. Lane 3: mouse ovaries without bestatin, with PMSG, and with starvation stress. Lane 4 : bestatin-treated mouse ovaries with PMSG stimulation and starvation stress. As a control for the amount of RNA loaded, the membrane was also probed with the constitutively expressed gene $\beta$-actin (lower panel).

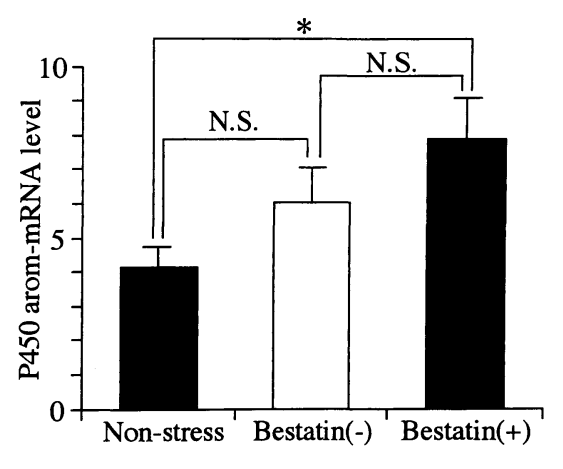

Fig. 5. The effects of bestatin administration on ovarian P450 arom-mRNA levels under starvation stress. Ovarian P450 arom-mRNA level in each group was expressed relative to that in mice without bestatin treatment, without PMSG stimulation, and without starvation stress. Bars indicate the mean \pm SEM $(* P<0.05)$.

of P450arom mRNA was also evident in PMSGtreated mice under starvation stress, and its expression was increased about 2 fold by the administration of bestatin (Fig. 4, lanes 3 and 4). The mean P450arom mRNA level of 5 experiments calculated by densitometric scanning was significantly higher in the bestatin-treated stressed mice than that in the non-stress mice (Fig. 5).

\section{Discussion}

Krulich et al. reported that the release, not only of ACTH but also of PRL, is increased in rats by acute stress, even minor stress such as handling, and that the release of $\mathrm{GH}$ and $\mathrm{LH}$ is decreased [19]. These conditions can be explained in part by an interplay of hypothalamic releasing factors, endorphin and cathecholamines [20]. In general, animals are sensitive to immediate changes in their environment, to alternations in their normal daily routine, or to certain management procedures [21]. For example, a new routine management may suppress ovulation of ewes [22, 23]. Food deprivation, in the physiological range, was sufficient to reduce the number of ova released in golden hamsters [24] and rats [25]. Food deprivation on days 1 and 2 of the estrus cycle also retards follicle development, decreases plasma estradiol level, and inhibits the LH surge in Syrian 
hamsters [26]. It is therefore well known that stress affects the central nervous system and suppresses the secretion of endogenous gonadotropins. On the other hand, the effect of the stress on peripheral reproductive organs has rarely been investigated. In this study, we used two stress conditions, continuous lighting for $72 \mathrm{~h}$ and starvation for 24 $h$. Under these conditions, the number of ovulated oocytes in the mice treated with PMSG-hCG was noticeably reduced, and the serum concentration of estradiol $48 \mathrm{~h}$ after PMSG administration was also attenuated. These findings indicate that the stress of continuous lighting and starvation interferes with the ovarian response to exogenous gonadotropins. In other words, stress directly inhibits the reproductive function at the ovarian site. There are many patients whose ovaries respond poorly to endogenous and/or exogenous gonadotropin stimulation with no definitive hypothalamic-pituitary disorders, but their classification and etiology have not yet been established. This study showed that stress is one of the causes of a poor ovarian response.

By using these models in which ovarian response to gonadotropins was impaired, we examined the effect of bestatin on follicular growth and ovulation. The number of ovulated oocytes was significantly increased by bestatin treatment and the serum concentration of estradiol $48 \mathrm{~h}$ after PMSG administration was increased about two-fold by bestatin treatment. These findings suggest that bestatin enhances the response of ovarian cells to exogenous gonadotropins. Since bestatin did not improve weight gain, it may have a direct effect on the ovaries.

The precise mechanisms of the suppressive effect of stress and the stimulatory effect of bestatin on ovarian follicular growth and ovulation is unclear. In spite of starvation conditions, P450arom mRNA expression was also clearly induced by PMSG. The mRNA levels measured by densitometric scanning of the autoradiograph showed that PMSG-induced P450arom mRNA expression under starvation conditions without bestatin treatment was not less than that of non-stress mice. This suggests that the main sites impaired by the stress are thecainterstitial cells. In porcine granulosa cell culture, bestatin enhanced FSH-stimulated progesterone and estradiol production [27]. By means of a follicle organ culture system derived from 15-day-old immature ICR mice, we observed that bestatin enhances estradiol production in the presence of FSH (unpublished data). This study showed that the expression of P450arom mRNA in the ovary treated with PMSG and bestatin under stress conditions was higher than that treated with PMSG under non-stress conditions. We therefore speculate that the effect of bestatin on follicular maturation is partially due to its enhancing action on granulosa cells in aromatase activity induced by FSH. In this study, we obtained no evidence suggesting that bestatin recovers the general condition of stressed mice, since bestatin did not improve weight gain. However, it is also possible that bestatin improved the general environment including the hypothalamus-pituitary-adrenal axis in stressed mice and enhanced the response of ovaries to gonadotropins.

In conclusion, this study showed that stress inhibits the ovarian response to gonadotropins and that bestatin restores the poor ovarian response suppressed by stress. Although the precise mechanism of the effect of bestatin remains to be further clarified, these findings suggest that bestatin will be clinically useful in the reproductive field.

\section{Acknowledgments}

We are grateful to Mr. Daniel Mrozek for reading the manuscript and Ms. Hisako Takahashi for technical assistance with RIA.

This work was supported in part by Grants-inAid for Scientific Research (no. 09671673, 09671674, 09671676).

\section{References}

1. Fujiwara $H$, Maeda $M$, Imai $K$, Fukuoka $M$, Yasuda K, Horie K, Takakura K, Taii S, Mori T (1992) Differential expressions of aminopeptidase $\mathrm{N}$ on human granulosa cells and theca cells. J Clin Endocrinol Metab 74: 91-95.

2. Fujiwara $H$, Maeda M, Ueda M, Fukuoka $M$, Yasuda 
K, Imai K, Takakura K, Mori T (1993) A differentiation-related molecule on the cell surface of human granulosa cells. J Clin Endocrinol Metab 76: 956-961.

3. Sanderink GJ, Artur Y, Siest G (1988) Human aminopeptidases: A review of the literature. J Clin Chem Clin Biochem 26: 795-807.

4. Ward PE, Benter IF, Dick L, Wilk S (1990) Metabolism of vasoactive peptides by plasma and purified renal aminopeptidase M. Biochem Pharmacol 40: 1725-1732.

5. Serrano L, Neira JL, Sancho J, Fersht AR (1992) Effects of alanine versus glycine in $\alpha$-helices on protein stability. Nature 356: 453-455.

6. Fujiwara H, Maeda M, Imai K, Fukuoka M, Yasuda K, Takakura K, Mori T (1992) Human luteal cells express dipeptidyl peptidase IV on the cell surface. J Clin Endocrinol Metab 75: 1352-1357.

7. Nakamura K, Fujiwara H, Nakayama T, Goto $Y$, Tachibana T, Suginami H, Ueda M, Maeda M, Mori $T$ (1996) An aminopeptidase inhibitor, bestatin, enhances gonadotropin-stimulated ovulation in mice. Hum Reprod 11: 1952-1957.

8. Umezawa $H$, Aoyagi $T$, Suda $H$, Hamada $M$, Takeuchi $T$ (1976) Bestatin, an inhibitor of aminopeptidase B, produced by actinomycetes. $J$ Antibiot Tokyo 29: 97-99.

9. Rich DH, Moon BJ, Harbeson S (1984) Inhibition of aminopeptidase by amastatin and bestatin derivatives. Effect of inhibitor structure on slow binding processes. J Med Chem 27: 417-422.

10. Müller WE, Schuster DK, Zahn RK, Maidhof A, Leyhausen G, Falke D, Koren R, Umezawa H (1982) Properties and specificity of binding sites for the immunomodulator bestatin on the surface of mammalian cells. Int J Immunopharmacol 4: 393-400.

11. Mathé $G$, Umezawa $H$, Misset JL, Brienza $S$, Canon $C$, Musset M, Reizenstein P (1986) Immunomodulating properties of bestatin in cancer patients. A phase II trial. Biomed Pharmacother 40: 379-382.

12. Goto $Y$, Noda $Y$, Narimoto $K$, Umaoka $Y$, Tokura T, Mori T (1992) Pregnancy achieved by transferring blastocysts into endometrial stroma in mice. Hum Reprod 7: 890-893.

13. Natsuyama S, Noda $Y$, Yamashita M, Nagahama $Y$, Mori T (1993) Superoxide dismutase and thioredoxin restore defective p34cdc2 kinase activation in mouse two-cell block. Biochim Biophys Acta 1176: 90-94.

14. Yasuda K, Fukuoka M, Taii S, Takakura K, Mori T (1990) Inhibitory effects of interleukin-1 on folliclestimulating hormone induction of aromatase activity, progesterone secretion, and functional luteinizing hormone receptors in cultures of porcine granulosa cells. Biol Reprod 43: 905-912.

15. Higuchi $T$, Kanzaki $H$, Nakayama $H$, Fujimoto $H$, Hatayama H, Kojima K, Iwai M, Mori T, Fujita J
(1995) Induction of tissue inhibitor of metalloproteinase 3 gene expression during in vitro decidualization of human endometrial stromal cells. Endocrinology 136: 4973-4981.

16. Takabatake K, Fujiwara H, Goto $Y$, Nakayama T, Higuchi T, Fujita J, Maeda M, Mori T (1997) Splenocytes in early pregnancy promote embryo implantation by regulating endometrial differentiation in mice. Hum Reprod 12: 2102-2107.

17. Terashima M, Toda K, Kawamoto T, Kuribayashi I, Ogawa Y, Maeda T, Shizuta Y (1991) Isolation of full-length cDNA encoding mouse aromatase P450. Arch Biochem Biophys 285: 231-237.

18. Tokunaga K, Taniguchi H, Yoda K, Shimizu M, Sakiyama S (1986) Nucleotide sequence of a fulllength cDNA for mouse cytoskeltal beta-actin mRNA. Nucleic Acids Res 16: 2829.

19. Krulich L, Hefco E, Illner P, Read CB (1974) The effect of acute stress on the secretion of LH, FSH, prolactin and $\mathrm{GH}$ in the normal rat, with comments on their statistical evaluation. Neuroendocrinology 16: 293-311.

20. McCann SM, Xu RK, Pan G (1988) Central mechanism involved in stress-induced alternations in pituitary hormone secretion in the rat: Clues for the mechanism of stress-induced hypogonadism. In: Genazzani AR, Montemagno U, Nappi C, et al. (eds) The Brain and Female Reproductive Function. Parthenon Publ. Co., Carnforth (U.K.): 285-290.

21. Moberg GP (1990) How behavioral stress disrupts the endocrine control of reproduction in domestic animals. J Dairy Sci 74: 304-311.

22. Doney JM, Gunn RG, Griffiths JG (1973) The effect of premating stress on the onset of oestrus and ovulating rates in Scottish Blackface ewes. J Reprod Fertil 35: 381-384.

23. Doney JM, Gunn RG, Smith WF (1976) Effects of pre-mating environmental stress, $\mathrm{ACTH}$, cortisone acetate or metyrapone on oestrus and ovulation in sheep. J Agric Sci 87: 127-132.

24. Morin LP (1986) Environment and hamster reproduction: Responses to phase-specific starvation during estrous cycle. Am J Physiol 251: R663-669.

25. Knuth UA, Friesen HG (1983) Starvation induced anoestrus: Effect of chronic food restriction on body weight, its influence on oestrous cycle and gonadotropin secretion in rats. Acta Endocrinol Copenh 104: 402-409.

26. Schneider JE, Wade GN (1989) Availability of metabolic fuels controls estrus cyclicity of Syrian hamsters. Science 244: 1326-1328.

27. Tachibana T, Fujiwara $H$, Suginami $H$, Nakamura K, Honda T, Yamada S, Maeda M, Mori T (1996) An aminopeptidase inhibitor, bestatin, enhances progesterone and oestradiol secretion by porcine granulosa cells stimulated with follicle stimulating hormone in vitro. Hum Reprod 11: 497-502. 